\title{
Das digitale Füllhorn
}

Eine Wundermaschine, die alles herstellt. Marmorähnliche Sandsteine jeder Grösse, dauerhaft und kunstvoll [1, 2], Lebensmittel, Ersatzteile für Auto und Hausgeräte, Kunstobjekte, Spielzeug und vielleicht einen zweiten Replikator gleicher Bauart. Wenn der US-Präsident Barack Obama recht hat, soll jeder Konsument fast jedes Objekt einfach ausdrucken können. Die Finanzmärkte haben reagiert, es gibt inzwischen Anlageprodukte, die darauf bauen, dass dem dreidimensionalen Drucker die Zukunft gehört.

Die Technologie der 3-D-Drucker entwickelt sich rasant. High-EndGeräte können beliebige Objekte einscannen und Kleinserien produzieren. Metalle in Pulverform, Polymere und Keramik werden durch Laser- oder Elektronenschmelzen Lage um Lage miteinander verbacken. Die Stereolithographie kann Strukturen aus flüssigen Kunstharzen oder Sand schichtweise aushärten. Dank sinkenden Preisen sind schon heute Geräte für den Hausgebrauch möglich. Websites [3] liefern Gratispläne für alltägliche Gegenstände. Wer das Objekt nicht selber ausdrucken möchte, kann die CAD-Datei bei Online-Diensten hochladen und sich das Produkt liefern lassen.

Medizinische Anwendungen werden in unzähligen Labors vorangetrieben. Die ersten Anwendungen aus anorganischem Material sind schon im Einsatz. Etwa eine Herzpumpe aus Keramik, Zahnimplantate oder massgeschneiderte Prothesen. Biodrucker sollen Gewebe herstellen, indem gewöhnliche oder Stammzellen, in eine flüssige Gelform gespritzt oder in einem Kollagengerüst verankert, zeilenweise zusammenwachsen. Eine Technik, die bereits die Herstellung kleinerer Stücke von Haut, Knorpel und Knochen ermöglicht. Lebergewebe aus bis zu zwanzig Zellschichten soll Medikamententeste vereinfachen, Herzzellen sollen kleinere Reparaturarbeiten leisten, Fettgewebe Implantate nach Lumpektomie ermöglichen. Ein Problem des «Tissue Engineering» ist die Durchblutung, was mit ein Grund sein mag, dass die Entwicklung von Knorpelgewebe, trotz der komplexen Chondrozyten-Struktur, schon weit fortgeschritten ist. Bei gezüchteten Herzklappen laufen die ersten klinischen Versuche. Sie wären besonders für Kinder geeignet, da sie mit dem Herzen mitwachsen. In Tiermodellen wurden komplette Blutgefässe aus körpereigenen Zellen als Bypässe erfolgreich eingesetzt. Nur vollständige Organe gehören wohl noch lange nicht zum Repertoire.

3-D-Druck materialisiert. Eine Firma wie «Modern Meadow» will in den USA bis 2050 den ersten künstlichen Hamburger auf den Markt bringen. Die zukünftige Weltbevölkerung soll auf das Schlachten der Tiere verzichten können. Die neuen Verfahren eignen sich für alle Herstellungsprozesse. Für Design, Kunst und Architektur sind sie schon fast Routine. Wo Gussformen entfallen, Schleifen, Bohren und Fräsen überflüssig sind, wird Material gespart. Wenn Druckdaten statt Güter herumgeschickt werden, könnte das die Logistik tiefgreifend verändern. Auch Waffen lassen sich produzieren. Der Fall des Studenten, der die druckreifen Baupläne für eine Pistole kostenlos ins Web stellte, machte weltweit Schlagzeilen. Chancen und Risiken sind, wie immer, kaum absehbar, Ethikkommissionen, Gesetzgeber und Prognoseinstitute rennen der Entwicklung hinterher. Nachträglich wird es dann jeder gewusst haben.

Einer, der sich intensiv als Science-FictionSchriftsteller mit dieser Entwicklung befasste, ist Andreas Eschbach, Autor des Bestsellers «Das Jesusvideo». In seinem Roman «Herr aller Dinge» [4] beschreibt er Aufstieg und Fall eines Genies, das für jeden Haushalt eine Wundermaschine konstruiert, die jedes bisherige Konzept von Besitz obsolet macht. Seine Vision sind Nanomaschinen, die Materie auf der Ebene der Atome manipulieren: «Sie können die ganze Welt neu gestalten, wenn man ihnen den Befehl dazu erteilt - oder sie zerstören, natürlich.» Die 3-D-Drucker wären, gemäss diesem Szenario, eine Art Vorhut der neuen wackeren Welt.

Erhard Taverna 